\title{
A cross sectional study on contraceptive knowledge, attitude and practice among teenage girls in secondary schools in Wanging'ombe district - Njombe Region.
}

\section{Luwoneko B. Mbilinyi, (MPH)}

Muhimbili University of Health and Allied Sciences

Dr Candida Moshiro,PhD ( $\nabla$ cmoshiro@gmail.com)

Muhimbili University of Health and Allied Sciences

\section{Research Article}

Keywords: Knowledge, Access, Attitudes, Contraceptive methods, Teenage pregnancy

Posted Date: April 29th, 2020

DOl: https://doi.org/10.21203/rs.3.rs-25841/v1

License: (c) (i) This work is licensed under a Creative Commons Attribution 4.0 International License. Read Full License 


\section{Abstract}

Background: Low contraceptive knowledge and practice among sexually active teenage girls in secondary schools remain a significant issue in Tanzania. This accelerates the problem of teenage pregnancy which takes a heavy toll on teenage girls' health and education well-being. Assessing the knowledge, attitude, and practice of contraceptive methods among teenage girls in secondary schools is of crucial importance in order to alleviate the problem.

Methods: A cross sectional survey was done involving 600 school girls. A questionnaire was used to gather information on demographic characteristics, knowledge on contraceptive methods, use, access, attitude and knowledge on the consequences of teenage pregnancy. Descriptive statistics were used to summarize demographic characteristics. Multivariate logistic regression analysis was used to analyze factors associated with knowledge on contraceptive methods while controlling for potential confounders. Odds ratios and $95 \%$ confidence intervals were computed.

Results: Sixty percent had knowledge on at least one contraceptive method. Among sexually active teenagers, fifteen percent reported to have ever used any form of contraceptive and ten percent were currently using contraceptives. Factors that were significantly associated with knowledge on any contraceptive methods were older age, higher class level, Muslim religion, urban residence, type of school, public school and middle-income economic condition. while teenage attitude towards contraceptives was positive (99.7\%). About two thirds of the girls had knowledge on the consequences of teenage pregnancy.

Conclusion: This article reveals that knowledge and use of contraceptive methods is still unsatisfactory and knowledge on the consequences of teenage pregnancy is unsatisfactory. The government and other stakeholders need to come up with effective interventions to alleviate the problem.

Keywords: Knowledge, Access, Attitudes, Contraceptive methods, Teenage pregnancy.

\section{Introduction}

The idea of contraceptives as a means of birth control in Tanzania has changed significantly over years, with some totally opposed and others accepting it. Traditionally it was unacceptable to fall pregnant before marriage, but cultural norms have shifted and having a teenage pregnancy is now not seen as immoral.

The attitudes of healthcare providers also leads to poor contraceptive use by teenagers, since they are denied access by being ridiculed, and despite having knowledge about contraceptives they end up becoming pregnant (1). Cultural beliefs within Black communities also prevent teenagers from gaining more information about sexuality, because culturally parents could not discuss sexual information with their children and thus leading to low knowledge on contraceptive methods among teenagers (1). Concrete sexual education and related information were not made available to the teens until they were faced with the trauma of teenage pregnancies, birth complications and Sexually Transmitted Infections (STIs) due to low knowledge of teenagers that led to wrong decisions and misconceptions about contraceptives (2). Additionally, teenagers face barriers that prevent use and/or consistent and correct use of contraception like stigma surrounding non-marital sexual activity and/or contraceptive use, fear attitude of side effects and lack of knowledge on correct use (3).

With global expansion of contraceptive information and services, contraceptive technologies have continually improved and contraceptive use prevalence has risen throughout most of the world. However, access to mainstream contraceptive methods is more limited in Africa than elsewhere as the proportion of sexually active teenage girls aged $15-49$ reporting use of a modern contraceptive method in Africa is $28.5 \%$ less than half the average throughout the world (4). Statistics show the contraceptive use prevalence among sexually active teenage girls aged $15-49$ years is $32 \%$ in Tanzania (5).

With increasing onset of sexual activity, teenage girls are exposed early to unplanned and unprotected sexual intercourse leading to teenage pregnancies and invariably abortions especially very common in many Sub-Saharan African countries where persistent high rates of unmet need for family planning and low rates of contraceptive use are reported (6).

Approximately 16 million girls aged 15 to 19 years and 2.5 million girls under 16 years give birth each year in low- and middle-income countries (7). Teenage mothers face higher risks of eclampsia, puerperal endometritis, and systemic infections than women aged 20 to 24 years (7). Bisika et al. (2007) also indicated that in low- and middle-income countries, more teenage girls die due to pregnancy-related conditions, and unsafe abortions account for a great deal of teenage morbidity. Statistics show the majority of unsafe abortions occurred in $2010-2014,97 \%$ occurred in low- and middle-income countries in Africa, Asia and Latin America (8).

Tanzania Demographic and Health Survey identified that $20 \%$ teenagers aged 15 to 19 years are sexually active (9). In addition, girls (14\%) are three times more likely than boys (5\%) of being sexually active before the age of 15 years (10). Furthermore, teenage girls in Tanzania have a HIV prevalence rate of $4 \%$, compared to boys (3\%) of the same age group, HIV/AIDS in Tanzania is primarily transmitted through unprotected sexual intercourse and youths accounts for over $60 \%$ of the new HIV infection (11). Apart from the risk of HIV/AIDS infection, teenage girl's experiences several social consequences of teenage pregnancies, such as early marriages and child bearing, expulsion from schools, domestic violence or abandonment from parents and peers alike (12).

Henceforth, since most teenagers in Tanzania are sexually active and experience consequences of unprotected sexual intercourse, particularly girls, it is worthy to conduct a study that will assist intervention programs to raise teenage knowledge, use and access on contraceptive methods. The findings will be useful in providing information to teenagers so that they develop knowledge, attitudes, values and skills needed to achieve behavioral changes necessary to protect themselves and their peers from consequences related to unwanted pregnancy and sexually transmitted infections, including HIV/AIDS.

\section{Methods}


The study adopted an analytical cross-sectional study design. A cross sectional study measure simultaneously the exposure and outcome in a given population and in a given geographical area at a certain time (13).

Study setting

The geographic domain of the study was in Wanging'ombe District. Wanging'ombe District is located in the southern highlands of Tanzania in Njombe region. According to the 2012 census, it has 161,816 residents and 39,057 adolescents and teenagers aged 10 to 19 years respectively (14). It has 16 wards (Igima, Saja, Uhambule, Ulembwe, Usuka, Wangama, Wanging'ombe Igosi, Ilembula, Imalinyi, Kidugala, Kijombe, Kipengele, Luduga, Makoga, Mdandu) and 16 public secondary schools respectively (14).

\section{Participants}

All teenage girls in secondary schools in Wangingombe District aged between 13 and 19 years respectively were taken.

\section{Eligibility criteria}

All teenage school girls in secondary schools in Wangingombe District aged $13-19$ years were included in the study.

\section{Variables}

\section{Outcome Variable}

The outcome variable was knowledge on contraceptive methods. This variable was defined as knowledge of any modern contraceptive method.

\section{The independent variables}

The independent variables for this study were socio-demographic characteristics such as age, family composition, religion, residence. Also, other variables included were attitudes towards contraceptive use, education level of school girls, type of school, school ownership and economic condition.

\section{Study size}

A single sample proportion formula was applied to determine the study size following the following assumptions: The proportion of teenagers with knowledge on contraception was $75 \%$ based on the study done in 2010 by Mung'ong'o. $95 \%$ confidence level, $5 \%$ absolute level of precision and $2 \%$ design effect were considered. Moreover, $10 \%$ of non-response rate was applied providing a final sample size of 640 study size.

\section{Sampling technique}

The researcher employed multistage sampling method. On the first stage, a researcher selected 4 wards from the list of 16 wards in Wanging'ombe district by using a systematic random sampling method. Every $4^{\text {th }}$ ward was selected from the list of 16 wards. The second stage involved stratification of schools into public and private followed by a random sampling of 1 school from each of the 4 selected wards. In the third stage, a probability proportionate sampling method was used to select students from each selected school. The classes that were involved were form 1 , form 2 , form 3 and form 4 . In each class, students were selected by simple random method through lottery method. Moreover, in classes where there are streams like A, B C etc, the researcher divided the number of total class sample by the number of streams in order to get equal number of students in every streams of classes. The students in each stream and classes were selected randomly after establishing the sampling frame of teenage girls aged 13-19 years.

\section{Statistical methods}

\section{Data collection instruments}

The researcher used a questionnaire as an instrument of data collection that comprised of a series of questions that were administered to respondents. The questionnaire was prepared in English translated to Kiswahili language which is the best medium of communication. The back translation (Kiswahili to English) was made to make sure the meaning and content are maintained in the Kiswahili version. The questionnaire was adopted from the WHO standard guide (World Health Organization, 2002) and from other literature. Pre-testing of the questionnaire (to make sure questions are clear and the flow was acceptable) was done and adjusted in order to fit the context of this study.

\section{Data collection process}

Data were collected by the Principal investigator with four research assistants (RAs) by using self-administered questionnaires. The RAs were females from Ilembula Nursing School. A three-day orientation process was carried out prior to the commencement of actual data collection. Topics covered included familiarizing with objectives of the study, sampling process, administering the questionnaire with an emphasis on research ethics and informed consent procedures. Moreover, the RAs were oriented to the procedures to interact well with study participants and to handle well the study tools

\section{Data management and analysis}

All analyses in the study were performed using SPSS version 22. Descriptive statistics was used to summarize demographic characteristics. Frequencies and percentages were used to summarize categorical data. For continuous data, mean and its corresponding standard deviation was computed. The Chi-square 
test was used to assess association between a dependent variable and each of the categorical independent variables. Odds ratios and $95 \%$ confidence intervals were used to determine the strength of the association. Moreover, multivariate logistic regression analysis was used to analyse factors associated with knowledge on contraceptive methods while controlling for potential confounders. Variables that had a $p<0.2$ in the bivariate analysis were included in the multivariable model. A p-value of less than 0.05 was used as a cut-off point for assessing statistical significance.

\section{Ethical consideration}

The researcher sought ethical approval from Muhimbili University of Health and Allied sciences (MUHAS). Then ethical approval was taken to the District education officer to seek a permit for conducting the research. Moreover, informed consent was sought from respondents after giving them sufficient information. Participation to the study was voluntary, and minimal risks of researching on individual sexual issues in the classroom was controlled by maximizing confidentiality and privacy whereby teachers' presence was not allowed during data collection process in the class. Furthermore, the respondents were assigned with numbers so as to ensure maximum confidentiality of their information.

\section{Results}

\section{Socio-demographic characteristics}

The study included 600 respondents (participation rate $=94 \%$ of the original estimated sample size of 640 ). Forty (6.25\%) students did not consent to participate for undisclosed reasons. Their age ranged from 13 to 19 years with a mean of $16.2(\mathrm{SD}=1.6)$ years. The majority $(38.5 \%)$ were aged $15-16$ years, $98.2 \%$ reported that both parents were still alive by the time of the study and $60.8 \%$ were living with either one or both parents when at home (Table 1 ).

Table 1: Distribution of study participants by background characteristics $(\mathrm{N}=600)$

\begin{tabular}{|c|c|c|}
\hline Characteristic & Number & Percent \\
\hline \multicolumn{3}{|l|}{ Age of Respondents } \\
\hline $13-14$ & 96 & 16 \\
\hline $15-16$ & 231 & 38.5 \\
\hline $17-18$ & 220 & 36.7 \\
\hline 19 & 53 & 8.8 \\
\hline \multicolumn{3}{|l|}{ Family composition } \\
\hline Have parents & 589 & 98.2 \\
\hline Have no parents & 11 & 1.8 \\
\hline \multicolumn{3}{|l|}{ Caretaker at home } \\
\hline Parents & 365 & 60.8 \\
\hline A guardian & 235 & 39.2 \\
\hline \multicolumn{3}{|l|}{ Class Level } \\
\hline Form 1 & 181 & 30.3 \\
\hline Form 2 & 157 & 26.2 \\
\hline Form 3 & 133 & 22.2 \\
\hline Form 4 & 129 & 21.5 \\
\hline \multicolumn{3}{|l|}{ Type of school } \\
\hline Mono sex & 282 & 47 \\
\hline Mixed sex & 318 & 53 \\
\hline \multicolumn{3}{|l|}{ Religion } \\
\hline Christians & 325 & 54.2 \\
\hline Muslims & 253 & 42.2 \\
\hline SDA & 22 & 3.7 \\
\hline \multicolumn{3}{|l|}{ Residence } \\
\hline Urban & 551 & 91.8 \\
\hline Rural & 49 & 8.2 \\
\hline \multicolumn{3}{|l|}{ School ownership } \\
\hline Public school & 569 & 94.8 \\
\hline Private school & 31 & 5.2 \\
\hline \multicolumn{3}{|l|}{ Sexually active } \\
\hline Yes & 81 & 13.5 \\
\hline No & 519 & 86.5 \\
\hline \multicolumn{3}{|l|}{ Previous contraceptive use } \\
\hline Yes & 12 & 2 \\
\hline No & 588 & 98 \\
\hline \multicolumn{3}{|c|}{ Discussion on contraceptives at School } \\
\hline Yes & 21 & 3.5 \\
\hline No & 579 & 96.5 \\
\hline \multicolumn{3}{|c|}{ Discussion on contraceptives at home } \\
\hline Yes & 0 & 0 \\
\hline No & 100 & 100 \\
\hline \multicolumn{3}{|c|}{ Health professionals provide information on contraceptives } \\
\hline Yes & 357 & 59.5 \\
\hline No & 243 & 40.5 \\
\hline \multicolumn{3}{|l|}{ Economic condition } \\
\hline Low status & 324 & 54 \\
\hline Middle status & 276 & 46 \\
\hline
\end{tabular}


About $60 \%$ of respondents reported that they knew at least one contraceptive method (Table 2). The most known contraceptive method was condoms (57.7\%) followed by pills (38.3\%) and injection (10\%). The major source of information on contraceptive methods reported by respondents was the media (59.5\%) followed by health personnel $7 \%$.

Table 2: Knowledge on contraceptive methods $(n=600)$

\begin{tabular}{ll}
\multicolumn{1}{c}{ Method } & Number $(\%)$ \\
\hline Any method & $361(60.2)$ \\
Jondoms & $346(57.7)$ \\
\hline Pills & $230(38.3)$ \\
[njection & $62(10.3)$ \\
Male sterilization & $21(3.5)$ \\
[UD & $8(1.3)$ \\
Periodic abstinence & $8(1.3)$ \\
\hline Withdrawal & $4(0.7)$ \\
\hline
\end{tabular}

Access and use of contraceptive methods among sexually active teenage girls

By the time of the survey, 81 (13.5\%) girls reported to be sexually active. Their reported mean age at first sex was 17.1 (SD = 0.3$)$ years. The minimum and maximum reported age at sexual debut was 17 and 18 years respectively. However, eight students (9.8\%) reported being currently (within past six months) engaged in sexual activity.

Among the 81 sexually active girls, $14.8 \%$ reported to have ever used any form of contraceptive. The most common mentioned type of contraceptives used within the past six months was a male condom (67.9\%). Among those who never used any contraceptive method, (74.2\%) reported they had no knowledge about contraceptive methods while (23.8\%) reported that they did not know where to get them.

Moreover, among sexually active girls, 56 (69.1\%) of respondents reported to have sought contraceptive methods. Those who sought contraceptive methods reported that it is very difficult to access them and the most common reason for this difficulty was fear of stigma (52\%). Fifty-six (69.1\%) of respondents reported that they get contraceptive methods from pharmacies while 4 (4.9\%) reported that they get from health facility, 16 (19.7\%) reported to have missed contraceptive methods due to stock out.

\section{Attitude towards use of contraceptives}

Secondary school girls in Wanging'ombe District had different attitudes towards the use of contraceptives, but the overall attitudes towards contraceptive methods was positive. Findings show that, almost all students (99.7\%) agreed that contraceptive methods are beneficial. However, all agreed that contraceptive methods are harmful (99.7\%) while 65.5\% agreed that it is wise for them to use a contraceptive. Moreover, a majority of students ( $90.3 \%$ ) reported that discussing/communicating about contraceptives with my parents/sexual partner is helpful. Some students agreed that contraceptive methods are associated with promiscuity $(9.1 \%)$.

Univariate analysis on factors associated with knowledge on any contraceptive method

Univariate analysis findings revealed that, students aged 16 - 19 years had higher odds of having knowledge on any contraceptive method compared to those in age group $13-15$ years $(\mathrm{OR}=5.99,95 \mathrm{Cl}(4.16-8.61), \mathrm{P}<0.001)$. Furthermore, the odds of knowing any contraception method increased as the class level increased.

It was also found that students who are Muslims had higher odds of having knowledge on contraceptive methods compared to students who are Christians $(\mathrm{OR}=35.59,95 \mathrm{Cl}(19.47-65.07), \mathrm{P}<0.001)$. It appears also that, students who are studying in public schools had higher odds of having knowledge on any contraceptive method compared to students who are studying in private schools (OR=24.79, $95 \mathrm{Cl}(5.86-104.94), \mathrm{P}<0.001)$.

\section{Multivariate analysis of factors associated with knowledge on contraceptive methods among School girls}

Table 6 shows results on multivariate analysis of factors associated with knowledge on contraceptive methods among secondary school girls in Wanging'ombe District. Findings shows that the odds of having knowledge on contraceptive methods for students aged 16 - 19 years is 2.3 times significantly higher compared to students aged $13-15$ years, after adjusting for other factors $(\mathrm{OR}=2.30,95 \mathrm{Cl}(1.29-1.29)$, $\mathrm{P}=0.004)$. Moreover, the odds of knowing any contraception method among students increased significantly as the class level increased after controlling for other factors.

It was also found that, after adjusting for other variables the odds of having knowledge on any contraceptive methods for students from middle income families is 30.3 times significantly higher compared to students from low income families $(P<0.001)$.

Table 3: Access and use of contraceptive methods among sexually active teenage girls $(n=81)$ 


\begin{tabular}{lcc}
\hline [TEM & Number (n=81) & Percent \\
\hline Ever sought contraceptive methods from a health facility & 56 & 69.1 \\
[t is difficult to get contraceptive in health facility & 36 & 44.4 \\
\hline [ get contraceptive from pharmacies & 56 & 69.1 \\
\hline [ get contraceptive from health centres & 4 & 4.9 \\
\hline Ever missed a contraceptive due to stock out at health facility & 16 & 19.7 \\
\hline Ever used any form of contraceptive in lifetime & 12 & 14.8 \\
\hline Used any contraceptive method in the past 6 months & 8 & 9.8 \\
\hline
\end{tabular}

Table 4: Attitude towards the use of contraceptives $(n=600)$ Attitude statement

Strongly agree/agree Neutral $\quad$ Strongly disagree/disagree

\begin{tabular}{|c|c|c|c|}
\hline Contraceptives are beneficial & $598(99.7)$ & $2(0.3)$ & 0 \\
\hline Using contraceptive is harmful & $598(99.7)$ & $2(0.3)$ & 0 \\
\hline It is wise to use a contraceptive & $393(65.5)$ & \multicolumn{2}{|c|}{$203(33.8) 4(0.7)$} \\
\hline Discussing about contraceptives with parents & $1596(99.3)$ & $3(0.5)$ & $1(0.2)$ \\
\hline Contraception is associated with promiscuity & $56(9.1)$ & \multicolumn{2}{|c|}{$544(90.7) 1(0.2)$} \\
\hline
\end{tabular}

Table 5: Univariate analysis on factors associated with knowledge on any contraceptive methods

\begin{tabular}{|c|c|c|c|c|}
\hline Item & $\begin{array}{l}\text { Total } \\
\mathrm{n}=600\end{array}$ & $\begin{array}{r}\text { Know any method } \\
\text { No. (\%) }\end{array}$ & $P$ value & Crude OR $(95 \% \mathrm{CI})$ \\
\hline \multicolumn{5}{|l|}{ Age } \\
\hline $13-15$ & 221 & $75(33.9)$ & & $\operatorname{Re}$ \\
\hline $16-19$ & 380 & $287(75.5)$ & $<0.001$ & $5.99(4.16-8.61)$ \\
\hline \multicolumn{5}{|c|}{ Family composition } \\
\hline Have parents & 589 & $357(60.6)$ & & $\operatorname{Re}$ \\
\hline Have no parents & 11 & $4(36.4)$ & 0.12 & $0.37(0.10-1.28)$ \\
\hline \multicolumn{5}{|l|}{ Class level } \\
\hline Form 1 & 181 & $62(34.3)$ & & $\operatorname{Re}$ \\
\hline Form 2 & 157 & $59(37.6)$ & 0.53 & $1.16(0.74-1.80)$ \\
\hline Form $3 \& 4$ & 262 & $240(91.6)$ & $<0.001$ & $4.16(3.72-5.29)$ \\
\hline \multicolumn{5}{|l|}{ Type of school } \\
\hline Mono sex & 282 & $168(59.5)$ & 0.055 & $0.29(0.08-1.02)$ \\
\hline Mixed sex & 318 & $265(83.3)$ & & Ref \\
\hline \multicolumn{5}{|l|}{ Religion } \\
\hline Christians & 325 & $111(34.2)$ & & $\operatorname{Re}$ \\
\hline Muslims & 253 & $240(94.9)$ & $<0.001$ & $35.59(19.47-65.07)$ \\
\hline SDA & 22 & $10(45.5)$ & 0.29 & $1.60(0.67-3.84)$ \\
\hline \multicolumn{5}{|l|}{ Residence } \\
\hline Urban & 551 & $348(63.2)$ & $<0.001$ & $4.75(2.46-9.16)$ \\
\hline Rural & 49 & $13(26.5)$ & & Ref \\
\hline \multicolumn{5}{|l|}{ School ownership } \\
\hline Public & 569 & $359(63.1)$ & $<0.001$ & $24.79(5.86-104.94)$ \\
\hline Private & 31 & $2(6.5)$ & & Ref \\
\hline \multicolumn{5}{|c|}{ Economic condition } \\
\hline Low income & 324 & $116(35.8)$ & & Ref \\
\hline Middle income & 276 & $245(88.8)$ & $<0.001$ & $14.17(9.15-21.94)$ \\
\hline
\end{tabular}




\begin{tabular}{|c|c|c|c|}
\hline & Adjusted OR & $(95 \% \mathrm{CI})$ & P value \\
\hline 15 & \multicolumn{3}{|c|}{ Ref } \\
\hline 19 & \multicolumn{2}{|c|}{$2.30(1.29-4.10)$} & 0.004 \\
\hline \multicolumn{4}{|c|}{ ly composition } \\
\hline parents & \multicolumn{3}{|c|}{ Ref } \\
\hline : no parents & \multicolumn{2}{|c|}{$0.20(0.001-55.43)$} & 0.34 \\
\hline \multicolumn{4}{|l|}{; level } \\
\hline 11 & \multirow{2}{*}{\multicolumn{2}{|c|}{$1.19(0.65-2.15)$}} & \\
\hline 12 & & & 0.58 \\
\hline $13 \& 4$ & \multicolumn{2}{|c|}{$2.93(1.25-6.88)$} & 0.01 \\
\hline \multicolumn{4}{|l|}{ of school } \\
\hline ว sex & $0.01(0.001-0.13)$ & & $<0.001$ \\
\hline d sex & \multicolumn{2}{|l|}{ Ref } & \\
\hline \multicolumn{4}{|l|}{ rion } \\
\hline stians & \multicolumn{3}{|c|}{ Ref } \\
\hline \multirow[t]{2}{*}{ ims } & $1.54(0.35-6$ & & 0.57 \\
\hline & $1.22(0.49-3.09)$ & & 0.66 \\
\hline \multicolumn{4}{|l|}{ lence } \\
\hline in & \multicolumn{3}{|c|}{ Ref } \\
\hline 1 & $0.06(0.006-0.61)$ & & 0.02 \\
\hline \multicolumn{4}{|c|}{ ol ownership } \\
\hline ic & Ref & & \\
\hline ite & $0.05(0.002-1.082)$ & & 0.06 \\
\hline \multicolumn{4}{|c|}{ lomic condition } \\
\hline income & & Ref & \\
\hline lle income & $30.25(5.51-166.05)$ & & $<0.001$ \\
\hline
\end{tabular}

\section{Discussion}

Knowledge on contraceptive methods

This study aimed at determining knowledge about contraceptive methods and associated factors among teenage girls in secondary schools in Wanging'ombe district - Njombe region. The study revealed that a considerable number of secondary school girls had knowledge on contraceptive methods but it was not sufficient as it was reported to be $60.2 \%$. These findings vary slightly from the study conducted by Mung'ong'o et al, in Dar es Salaam Tanzania which reported that the level of knowledge on contraceptive methods among students in secondary schools was 75\% (16). There are other studies reported lower percentage of knowledge on contraceptives among teenage school girls than this study,

for instance, the study conducted in Oyo State - South West Nigeria reported that female secondary school students had a high knowledge on contraceptive knowledge, but only $58.1 \%$ of all students had a good knowledge (17). Moreover, there are numerous studies conducted in different parts of the world which revealed similar findings as this study, for example studies conducted in Rural Pakistan by Mustafa (2008) in Bangladesh (18), a study by (Kabir, 2008)(19), in Tanzania by Dangat \& Njau, (2013) (20), as well as in Nigeria by Idonije et al, (2011) (21) revealed that the level of knowledge on contraceptive methods among teenage girls in secondary schools is still low and unsatisfactory. The variations in the level of knowledge on contraceptive methods reported by various studies might be due to differences in socio - economic and demographic characteristics of study populations.

\section{Contraceptive use and access among secondary school girls}

The study found that use of contraceptives among interviewed sexually active school girls is still very low. The prevalent reasons for non-use of contraceptives reported was poor knowledge on contraceptives and lack of access to contraceptives. There are other studies that found the similar findings and some different findings, for instance studies done in Tanzania, Kenya, Ethiopia, Ghana, Nigeria, Uganda and India revealed almost the same findings (Mngodo, 2013; Somba et al., 2014; Sweya et al., 2016; Mung'ong'o et al., 2010a; Adeyinka et al., 2009; Ahmed et al., 2017; Asekun-Olarinmoye and Adebimpe, 2013; Fantahun et al., 1995; Mwambete and Mtaturu, 2006; Mung'ong'o et al., 2010b; Renjhen et al., 2010; Kagashe and Honest, 2013; Olajide et al., 2014; Nsubuga et al., 2016).

The most common mentioned type of contraceptive method used within the past six months was a male condom. This finding is consistent with findings from a study done among secondary school students in Dar es Salaam, Tanzania (16). The study done among secondary school students in Ekpoma, Nigeria found that condom was the major available contraceptive for the males (21). Another study among physically challenged in-school adolescents in Osun State, Nigeria found the same findings (22). Male condoms are preferably used by school girls with their sexual partners mainly because it is convenient to apply and has dual effects namely prevention of unintended pregnancies and protection against sexual transmitted infections including HIV infection. Moreover, the 
majority of sexually active girls in this study reported that it is very difficult to access contraceptive methods and the most prevalent reason was fear of stigma.

The main mentioned sources of information about contraceptive methods were media. There are other studies that found similar findings while other studies found different findings. For instance, in the study conducted among secondary school girls in Calabar, Nigeria it was found the main sources of contraceptive information were books/magazines and friends (28). Also, the study among senior high school students in Ahmedabad in India reported the prevalent sources of information mentioned were schools, books, friends, mass media and sexual partners (23).

Tanzanian Demographic Health survey 2016 found almost the same findings: the students reported hearing a family planning message on the radio ( $62 \%$ of females and $75 \%$ of males) (29). Teenagers were also exposed to family planning messages via television ( $31 \%$ of females and $47 \%$ of males) and newspapers/magazines (25\% of females and $35 \%$ of males) (9). In almost all studies media has been the most prevalent source of information.

\section{Attitudes towards Contraceptive use}

Overall, the attitudes towards contraceptive methods among school girls in this study is positive as majority of students perceived that contraceptives are beneficial (99.7\%) and also students were in favor of contraceptive methods (65.5\%), however there are some students who perceived that contraceptive methods are harmful (99.7\%) while others reported that contraceptive methods are associated with promiscuity (9.1\%). This study is consistent with the study of Opundo, 1998 in his study in Kisumu, Kenya found that over $77 \%$ of teenage school girls indicated positive attitude as they are in favour of contraceptive methods In Oyo-state in Nigeria Idowu et al., (2017) found that $55.3 \%$ of teenage school girls had positive attitudes towards family planning (17). A majority of secondary school girls are not taking any precaution to prevent teenage pregnancies for fearing side effects and perceived promiscuity. The girls need to be knowledgeable about side effects as far as contraceptives are concerned. Perceived promiscuity is a wrong perception that can be mitigated by educating the community

\section{Factors associated with knowledge on contraceptive methods}

The univariate and multivariate models of this study revealed that factors that were significantly associated with knowledge on contraceptive methods among teenage girls in secondary schools in Wanging'ombe District were older age, higher class level, type of school, religion, residence, school ownership and economic condition of parents at home. These findings differ from other studies such as the study conducted by Bugsa et al, (2014) in secondary schools in Ethiopia which revealed that factors associated with knowledge on contraceptive methods are age of respondents, marital status, primary source of information, and previous contraceptive use. Moreover, another study conducted in Ethiopia by Habitu et al (2015) reported that information about contraceptives, cultural acceptance, sexual intercourse, and attitudes towards contraceptive methods were associated with knowledge on contraceptive methods among teenage secondary school girls. Also, the study conducted by Sweya et al (2016) (24), Aghoja et al (2009) (25) as well as by Hossain et al (2018) (26) revealed several factors associated with knowledge on contraceptive methods such as education level, cultural factors, attitudes, religion, marital status, sexual active, beliefs, socio economic status, women age, low literacy levels and ineffective conveyance of health information by health care providers. The possible reasons behind these differences in findings might be differences in geographical settings and differences in socio demographic characteristics of study populations.

Knowledge on the consequences of teenage pregnancy on health and education

The study reveals that knowledge on the consequences of teenage pregnancy on adolescent health and education is relatively high (64\%). This finding is consistent with various studies which reported similar findings for example the study of Achema, Emmanuel, \& Moses, (2015) (27), Bhandari, (2015) (28), Kunene, (2014) (29) and Kanku \& Mash, (2014) (30). However, the reported knowledge is unsatisfactory as it is below $80 \%$, therefore it is worthy to introduce interventions in order to raise knowledge on the consequences of teenage pregnancy to the students.

\section{Conclusions}

Study findings show that the level of knowledge on contraceptive methods among teenage girls in secondary schools in Wanging'ombe District is moderate which poses a greater risk for teenage pregnancies. In addition, the use of contraceptive methods among sexually active school girls in Wanging'ombe District is still low which accelerates more risk to teenage pregnancies and therefore affecting their health status and education welfare. Access to contraceptive methods among sexually active teenage girls is still poor which put teenage girls at a greater risk to teenage pregnancies among secondary school girls in Wanging'ombe District. Older age, higher class level, Muslim religion, urban residence, being in a public school and middle-income economic condition were significantly associated with knowledge on any contraceptive method. Moreover, a majority of teenagers have positive attitudes towards contraceptive methods. Furthermore, the knowledge on the consequences of teenage pregnancy in health and education was unsatisfactory which indicates a greater risk for teenagers' welfare.

\section{Limitation of the study}

There are some limitations that are important to be noted: For instance, the use of cross-sectional study limited the study because it did not allow the establishment of causality. Moreover, the study relied on information reported by school girls on questions reflecting personal experience. Participants might not have readily responded to reproductive and sexual behavior questions adequately. Self-administered questionnaires were subject to information bias, and since the study touched sensitive issues specifically sexual activity, the possibility of concealment by the students could not be excluded. Female student nurses facilitated data collection and none of the school teachers was allowed to get into contact with students during data collection in order to allow confidentiality and freedom of expression among study participants; this might have minimized the problem of information bias. Measurement error in measuring knowledge on contraceptive methods was introduced, this might have led to over-estimation of study result. 


\section{Abbreviations}

CDC: Centers for Disease Control and Prevention; CRC: Committee on the Rights of a Child; GEWE: Gender Equality and Women Empowerment; MUHAS: Muhimbili University of Health and Allied Sciences; NBS: National Bureau of Statistics; TAMWA: Tanzania Media Women Association; TAWLA : Tanzania Women Lawyer's Association; TDHS: Tanzania Demographic and Health Survey; TGNP: Tanzania Gender Network Programme; UNICEF: United Nations International Children Emergency Fund; WHO: The World Health Organization; ZAFELA: Zanzibar Female Lawyer's Association.

\section{Declarations}

\section{Competing interests}

The author declares that he has no competing interests.

\section{Consent for publication}

Not applicable, no individual detail is presented.

\section{Authors' contributions}

LM prepared the introduction, literature review, methodology, data collection, analysis and results, discussion, formulated conclusion and recommendations.

CM did a critical review of the paper and approved the final manuscript.

\section{Acknowledgements}

The author would like to Thank Muhimbili University of Health and Allied Sciences (MUHAS) for full support on this study. Great Thanks to my supervisor Dr. Candida Moshiro from MUHAS for her enormous contribution, supervision and reviewing the manuscript.

\section{Funding}

Not applicable.

\section{Availability of data and materials}

All relevant data are within the manuscript. The datasets analyzed during the current study available from the corresponding author on reasonable request.

\section{Ethics approval and consent to participate}

Ethical clearance was obtained from Ethical Review Committee of Muhimbili University of Health and Allied sciences.

\section{Author details}

LM has a Master of Public Health from Muhimbili University of Health and Allied Sciences, Tanzania.

${ }^{1}$ Department of Public Health, School of Public Health and Social Sciences, Muhimbili University of Health and Allied Sciences, Dar es salaam, Tanzania.

\section{References}

1. Ehlers. Adolescent mothers ' knowledge and perceptions of contraceptives in Tshwane, South Africa. 2006;8(1):13-25.

2. Darroch JE, Singh S. Why is Teenage Pregnancy Declining? The Roles of Abstinence, Sexual Activity and Contraceptive Use Jacqueline E . Darroch Susheela Singh Occasional Report No . 1 December 1999. 1999;(1).

3. WHO. Adolescent pregnancy: Key facts. 2018;

4. WHO. Family planning / contraception. World Heal Organ. 2018;2018.

5. UNFPA. Reproductive health in Tanzania; Annual Report. 2018;

6. Okonofua F. Abortion and Maternal Mortality in the Developing World. J Obstet Gynaecol Canada. 2006;28(11):974-9.

7. UNFPA. Girlhood, Not Motherhood; Preventing Adolescent Pregnancy. United Nations Population Fund. 2015. 1-62 p.

8. WHO. Worldwide, an estimated 25 million unsafe abortions occur each year. 28 Sept. 2017;

9. TDHS. Tanzania 2015-16 Demographic Health Survey and Malaria Indicator Survey. Tanzania 2015-16 Demogr Heal Surv Malar Indic Surv [Internet]. 2015; Available from: https://www.dhsprogram.com/pubs/pdf/SR233/SR233.pdf

10. TDHS. Tanzania Demographic and Data Survey. 2010;

11. UNAIDS. United Republic of Tanzania. Popul Policy Compend. 2018;1-6.

12. Rondini S, Krugu JK, Harvest Y, Sexual A. Knowledge, attitude and practices study on reproductive health among secondary school students in Bolgatanga , upper east region, Ghana Knowledge, Attitude and Practices Study on Reproductive Health Among Secondary School Students in Bolgatanga , Upper. 2009;(April 2016). 
13. Hemed M (2015). Cross-sectional studies.

14. NBS. 2012 Population and Housing Survey. Population Distribution by Administrative areas. United Republic of Tanzania: National Bureau of Statistic,Ministry of Finance, and Zanzibar, Office of Chief Government Statistician, President's Office, Finance, Economy. 2013;65. Available from: https://www.guttmacher.org/sites/default/files/pdfs/pubs/or_teen_preg_decline.pdf

15. 2002 World Health Organization. World Health Survey Guide To Administration and Question By Question Specifications. World Heal Organ [Internet]. 2002; Available from: http://www.who.int/healthinfo/survey/whsshortversionguide.pdf

16. S. G. MUNG'ONG'O* VMABK. Knowledge, Attitude and Practice on Contraceptive Use among Secondary School Students in Dar es Salaam, Tanzania. East Cent African J Pharm Sci [Internet]. 2010;13(45):39. Available from: https://www.nber.org/papers/w15827.pdf

17. Idowu A, Aremu OA, Fehintola FO, Popoola GO. Knowledge, attitude and practice of contraception by female junior secondary school students in an urban community of Oyo-state, South west, Nigeria. Int J Reprod Contraception, Obstet Gynecol [Internet]. 2017;6(11):4759. Available from:

https://www.researchgate.net/publication/320698352_Knowledge_attitude_and_practice_of_contraception_by_female_junior_secondary_school_students. state_South_west_Nigeria/link/5a02a6c2aca2720df3cd8df6/download

18. Mustafa R, Afreen U, Hashmi HA. Contraceptive Knowledge, Attitude and Practice Among Rural Women. 2008;18(9):542-5. Available from: http://applications.emro.who.int/imemrf/jcpsp/jcpsp_2008_18_9_542_545.pdf

19. Kabir H, Saha NC, Oliveras E, Gazi R. Association of programmatic factors with low contraceptive prevalence rates in a rural area of Bangladesh. Reprod Health [Internet]. 2013;10(1):4-11. Available from: https://sci-hub.tw/https://reproductive-health-journal.biomedcentral.com/articles/10.1186/1742-475510-31

20. Dangat CM, Njau B. Knowledge, attitude and practices on family planning services among adolescents in secondary schools in Hai District, northern Tanzania. Tanzania J Heal Res Vol 15, Number 1, January 2013 [Internet]. 2013;15(1):1-8. Available from:

https://www.ajol.info/index.php/thrb/article/view/72984/74715

21. Idonije et al. A study on knowledge, attitude and practice of contraception among secondary school students in Ekpoma, Nigeria. JPCS Vol(2) - July-Sep 2011 [Internet]. 2011;2(2):22-7. Available from: www.arpapress.com/Volumes/JPCS/Vol2/JPCS_2_06.pdf

22. Olajide FO, Omisore AG, Arije OO, Afolabi OT, Olajide AO. Awareness and use of modern contraceptives among physically challenged in-school adolescents in Osun State, Nigeria. Afr J Reprod Health [Internet]. 2014;18(2):87-96. Available from:

https://www.ajol.info/index.php/ajrh/article/viewFile/104428/94509

23. Thaker R, Patel J, Desai R, Parmar J. Knowledge and practice regarding contraception and population control among higher secondary school students in Ahmedabad. Int J Med Sci Public Heal. 2015;4(1):77.

24. Msuya SE, Mahande MJ, Manongi R. Contraceptive knowledge, sexual behavior, and factors associated with contraceptive use among female undergraduate university students in Kilimanjaro region in Tanzania. 2016;109-15. Available from: https://www.dovepress.com/contraceptiveknowledge-sexual-behavior-and-factors-associated-with-co-peer-reviewed-fulltext-article-AHMT\#

25. Aghoja CO, Okonofua FE, Umueri C, Otayohwo R, Onowhakpor EA, Inikori KA. Factors associated with the Knowledge, Practice, and perceptions of contraceptions in rural Southern Nigeria. Ghana Med J [Internet]. 2009;43(3):115-21. Available from: https://www.ncbi.nlm.nih.gov/pmc/articles/PMC2810247/pdf/GMJ4303-0115.pdf

26. Hossain M, Khan M, Ababneh F, Shaw J. Identifying factors influencing contraceptive use in Bangladesh: Evidence from BDHS 2014 data. BMC Public Health [Internet]. 2018;18(1):1-14. Available from: https://bmcpublichealth.biomedcentral.com/track/pdf/10.1186/s12889-018-5098-1

27. Achema G, Emmanuel A, Ao M. Factors responsible for teenage pregnancy and its implication on adolescent health and education: Perception of secondary school students in Nigeria Factors responsible for teenage pregnancy and its implication on adolescent health and education: Percep. 2016; (September). Available from:

https://www.researchgate.net/publication/308361932_Factors_responsible_for_teenage_pregnancy_and_its_implication_on_adolescent_health_and_educ

28. Bhandari SD. Awareness on Consequences of Teenage Pregnancy among Adolescent at Ampipal VDC, Gorkha. J Adv Acad Res [Internet]. 2015;1(1):10-7. Available from: https://www.nepjol.info/index.php/JAAR/article/view/13506

29. Kunene PJ. Teenagers' knowledge of human sexuality and their views on teenage pregnancies. Curationis [Internet]. 2014;18(3):48-52. Available from: https://curationis.org.za/index.php/curationis/article/view/1363/1319

30. Kanku T. Attitudes, perceptions and understanding amongst teenagers regarding teenage pregnancy, sexuality and contraception in Taung. South African Fam Pract [Internet]. 2010;52(6):563-72. Available from: https://sci-hub.tw/10.1080/20786204.2010.10874048 